CLINICAL STUDY

\title{
Surgical outcomes and prognostic factors of transsphenoidal surgery for prolactinoma in men: a single-center experience with 87 consecutive cases
}

\author{
Xin $\mathrm{Qu}^{1}$, Min Wang ${ }^{1}$, Guodong Wang ${ }^{1}$, Tao $\mathrm{Han}^{1}$, Chengzhi Mou ${ }^{1}$, Lizhang $\mathrm{Han}^{1}$, Meng Jiang ${ }^{1}$, Yuanming $\mathrm{Qu}^{1}$, \\ Miao Zhang ${ }^{2}$, Qi Pang ${ }^{1}$ and Guangming $\mathrm{Xu}^{1}$ \\ ${ }^{1}$ Department of Neurosurgery and ${ }^{2}$ Department of Clinical Laboratory, Provincial Hospital Affiliated to Shandong University, Shandong University, \\ 324\#, Jingwu Road, Jinan 250021, People's Republic of China \\ (Correspondence should be addressed to G Xu; Email: guangmingxu@sdu.edu.cn)
}

\begin{abstract}
Context: Little systematic data on male prolactinomas treated with surgery are available. Objective: To clarify the clinical features and confirm the efficacy of transsphenoidal surgery for male prolactinomas and predictive factors after initial surgery.

Patients and methods: This retrospective study included 87 male patients with prolactinoma treated by transsphenoidal surgery at an academic medical center. Hormonal and visual status, remission rates, and the rate of tumor relapse, as well as predictive factors, were evaluated.

Results: Postoperative initial remission was achieved in $52.9 \%$ of patients. The remission rate was markedly higher in microadenomas $(83.3 \%)$ than in macroadenomas (44.9\%). Logistic regression analysis showed that the predictive factors of the early negative outcomes were high preoperative prolactin (PRL) levels and tumor invasion. After a median follow-up of 45 months, the long-term remission rate was $42.5 \%$, and relapse of hyperprolactinemia occurred in $19.6 \%$ of the cured patients. The 5-year recurrence-free survival was $78.2 \%$ (95\% confidence interval, 62.3-88.1\%). When surgery was followed by adjuvant treatment in uncured and recurrent patients, $78.8 \%$ of patients in the entire group in the absence of dopamine agonists obtained biochemical remission at the end of follow-up.

Conclusion: Transsphenoidal surgery is a viable treatment alternative for male prolactinomas. The remission rates of male patients with microadenomas and/or intrasellar macroprolactinomas by surgery alone remain excellent, and surgery followed by adjuvant therapy as necessary is required for optimizing management of male prolactinomas, especially for extrasellar macroprolactinomas. The early negative results are associated with preoperative PRL levels and tumor invasion.
\end{abstract}

European Journal of Endocrinology 164 499-504

\section{Introduction}

Prolactinomas are the most frequent hormonesecreting pituitary neoplasms and constitute $\sim 40 \%$ of all pituitary adenomas $(1,2)$. Prolactinomas in men are relatively rare in the clinical setting, in which the proportion of men to women is $\sim 1: 10$ (3), and are typically large relative to those in women (4). At present, dopamine agonists (DA) have been recognized to be the mainstay in the treatment of prolactinomas including male prolactinomas. However, Colao et al. (5) demonstrated in a prospective study that the recurrence rate of male prolactinomas after 24-96 months of Cabergoline withdrawal was $63 \%$, markedly higher than that of female prolactinomas (32\%). More recently, a meta-analysis showed that the proportion of patients with persisting normoprolactinemia after DA withdrawal was $21 \%$ in microprolactinomas and $16 \%$ in macroprolactinomas respectively, despite nearly all consisting of female prolactinomas (6). Furthermore, there are several other major drawbacks in DA including frequent side effects, extortionate price, and long-term administration (7-9). Some other studies have reported that drug resistance in males is remarkably more frequent relative to that in female patients $(24-30$ vs $5-18 \%)(10,11)$. Herein, surgery, especially transsphenoidal microsurgery, is still required for a number of patients with prolactinomas (12). However, the impact of transsphenoidal surgery on male prolactinomas is still a matter of debate. And there are scant symptomatically clinical data available regarding surgical therapy of male prolactinomas, and data have usually been analyzed in small sample sizes (13-15) or in a mixed cohort of women and men in the 
literature (16-19). We therefore performed a retrospective analysis for our results of surgical treatment in consecutive male prolactinomas to clarify the clinical features and confirm the efficacy and prognostic factors of transsphenoidal surgery for male prolactinomas.

\section{Patients and methods}

\section{Patients}

We retrospectively analyzed 87 consecutive male patients who underwent surgery for prolactinomas between January 1995 and June 2008 at the Department of Neurosurgery, Provincial Hospital affiliated to Shandong University, Jinan, People's Republic of China. The diagnosis of prolactinomas was postoperatively confirmed by immunohistochemical analysis. Indications for surgical therapy of prolactinomas are currently as follows: resistance to medical therapy, intolerance to DA, neurological deficits including rapid visual loss or cranial nerve palsies because of tumor apoplexy, cerebrospinal fluid leakage attributable to tumor shrinkage after medical therapy, cystic macroprolactinomas with neurological symptoms, and patient preference $(17,20)$. Of the 87 patients, 24 cases underwent surgery due to intolerance to DA, 15 due to resistance to DA, 9 cases because of tumor apoplexy causing neurological symptoms, and the other due to personal preference. Magnetic resonance imaging (MRI) was performed on all patients before surgery. Based on the largest diameter measured by preoperative MRI, tumors fell into two categories: microadenomas and macroadenomas (20). The latter was subdivided into intrasellar and extrasellar macroadenomas (16). Patients with Knosp grade 3 or 4 based on preoperative MRI and with intra-operative evidence of cavernous sinus tumor invasion were defined as true cavernous sinus invasion as previously described (21). Tumor volume was calculated as height $\times$ length $\times$ width $/ 2$ (22). All patients had undergone no previous surgical or radiation treatment for prolactinomas. Medical therapy with bromocriptine had been performed in 47 cases for 2-28 months but ceased at least 4 weeks before surgery. All operations were performed by two experienced neurosurgeons ( $\mathrm{Y} \mathrm{Qu}$ and $\mathrm{G} \mathrm{Xu})$. All patients underwent pernasal transsphenoidal surgery with the operating microscope (23). Ethics Committee approval was obtained from the Research Ethics Committee of Shandong University, People's Republic of China. Informed consent was obtained from all patients. All patients were followed up as outpatients 3 months after surgery and then at annual or biannual intervals. Follow-up information of patients outside our department was obtained by contacting the patients or their relatives by telephone or mail.

\section{Pre- and post-operative hormonal evaluations}

Endocrine assessment was routinely performed on the basis of morning fasting basal hormone levels before and after surgery. Serum prolactin (PRL) concentrations from all patients were measured using validated IRMAs. Reference values for men in our laboratory are 4-15 ng/ml. Initial biochemical remission was defined as postoperative normalization of a morning basal PRL level $(<15 \mathrm{ng} / \mathrm{ml})$ without dopaminergic therapy for at least 4 weeks before surgery (17). Follow-up remission was diagnosed with a morning basal PRL level $<15 \mathrm{ng} / \mathrm{ml}$ without DA therapy for at least 3 months at the latest follow-up (17). Recurrence was based on elevated PRL levels above the normal range during the follow-up period, regardless of symptoms and neuroradiological findings (16).

\section{Statistical analysis}

All statistical procedures were processed with the software package SPSS 15.0 for Windows (SPSS Inc., Chicago, IL, USA), except estimation of confidence intervals (CIs) which were estimated using Stata 9.2 (StataCorp LP, TX, USA). Differences between subgroups were analyzed using Student's $t$-test for normally distributed continuous data, which are reported as mean \pm s.e.M., and nonparametric test for non normally distributed continuous ones. Pearson's $\chi^{2}$ test was performed for categorical variables. Correlation coefficients were calculated by regression analysis. Binary logistic regression analysis was used to identify independent predictors of outcome/remission. Those variables that had a $P$ value $<0.10$ in the univariate analysis were entered. The Kaplan-Meier method was conducted to analyze recurrence of adenomas during the follow-up period. Recurrence-free survival was calculated from the date of surgical treatment to the date of recurrence and was dropped (censored) at the date of the last follow-up visit. A $P$ value of $<0.05$ was considered significant.

\section{Results}

\section{Patient characteristics}

The median age at surgery was 38 years (range, 17-69 years). The symptom duration ranged from 10 days to 120 months (median, 12 months). Mean preoperative morning serum PRL levels were $974.6 \pm 181.1 \mathrm{ng} / \mathrm{ml}$ (range, 40.5-12 $520 \mathrm{ng} / \mathrm{ml}$ ). Among them, there were 18 microadenomas and 69 macroadenomas, including 25 intrasellar and 44 extrasellar macroadenomas. Cavernous sinus invasion was observed in 30 patients (34.5\%). Headache occurred in 51 patients $(58.6 \%)$. Preoperative visual impairment occurred in 44 patients (50.6\%). A large proportion of patients presented with endocrine symptoms: decreased libido in 66 , impotence 
in 9, infertility in 3, galactorrhea in 3, and gynecomastia in 4 patients. Testosterone deficiency $(<2.8 \mathrm{ng} / \mathrm{ml})$ was present in 68 patients $(78.2 \%)$. The basal preoperative PRL level strongly correlated with adenoma volume in our series $(r=0.672, P<0.001)$ and preoperative testosterone level $(r=-0.223, P=0.019)$, but not with preoperative duration of symptoms $(r=0.030$, $P=0.393)$.

\section{Early results}

Transient diabetes insipidus occurred in 14 patients (16.1\%), and no patients developed permanent diabetes insipidus. Postoperative hematomas occurred in one $(1.15 \%)$ patient requiring a reoperation. Cerebrospinal fluide (CSF) leaks occurred in four cases and were successfully treated using external lumbar drainage. There were no vascular injuries, meningitis, mortality, or other morbidity in the subjects. The median postoperative duration of hospitalization was 5 days (range 3-15 days). In total, 90\% were discharged by postoperative day 5 .

The mean postoperative PRL level was 243.6 $\pm 43.1 \mathrm{ng} / \mathrm{ml}$ (range, 4-2100.8 ng/ml), which was markedly lower than the preoperative average value (974.6 $\pm 181.1 \mathrm{ng} / \mathrm{ml}, P<0.001)$. Early normalization of PRL levels was achieved in $15(83.3 \%)$ patients with microadenoma, and in $31(44.9 \%)$ patients with macroadenoma respectively. Among macroadenomas, $80.0 \%(20 / 25)$ of those with intrasellar adenomas and $25.0 \%(11 / 44)$ with extrasellar extension achieved early surgical remission with significant difference $(P<0.001)$. Only a minority of adenomas $(10.0 \%)$ with cavernous sinus invasion obtained surgical remission. Because of the similar rates of remission and all microadenomas lying in the sella turcica, patients with microadenoma and intrasellar macroadenoma were grouped as intrasellar adenomas (16, 24). Univariate analysis revealed that tumor diameter, preoperative PRL levels, extrasellar extension, and tumor invasion were related to surgical results, whereas the relationship between preoperative dopaminergic treatment and surgical outcomes was not found.

Statistically significant difference was found between the mean preoperative PRL level $(237.8 \pm 36.8 \mathrm{ng} / \mathrm{ml})$ in the remission group and that $(1801.3 \pm 340.0 \mathrm{ng} / \mathrm{ml})$ in the persistent group $(P<0.001)$. A multiple logistic regression analysis was used that included surgical outcome, age, tumor size, preoperative PRL level, tumor invasion, and prior bromocriptine therapy. A lower preoperative PRL value was the strongest predictor of initial remission $(P=0.001)$, and invasion into the cavernous sinus was also significant $(P=0.003)$.

\section{Long-term results}

The median duration to follow-up for the entire group was 45 months (range, 13-121 months). Two patients not cured were lost to follow-up. Of these male patients at the latest evaluation, 37 (42.5\%) were still in remission. Nine patients $(19.6 \%)$ experienced recurrence of hyperprolactinemia, and the median PRL concentration was $467.2 \mathrm{ng} / \mathrm{ml}$ (range, 78.3-982 ng/ml). Among these patients, seven had the visible tumors in MRI, and tumor volume ranged from 0.10 to $1.13 \mathrm{~cm}^{3}$ (median, $0.50 \mathrm{~cm}^{3}$ ). All relapses arose within the first 4 years after surgery. Figure 1 exhibits the recurrencefree survival curve by Kaplan-Meier analysis. The 5-year recurrence-free survival rate was $78.2 \%(95 \%$ CI, 62.3-88.1\%). Among these recurrent patients, two cases were microadenomas, and the rest were macroadenomas. The 5-year recurrence-free survival rate in 34 male patients with intrasellar tumors $(89.7 \%$; $95 \%$ CI, 71.4-96.6\%) was significantly different from that of the 12 patients with extrasellar adenomas by the logrank test $(45.5 \% ; 95 \% \mathrm{CI}, 16.7-70.7 \%, P=0.002$, Fig. 2). Univariate analysis of the time to relapse demonstrated that the postoperative PRL level and extrasellar extension were associated with recurrence ( $P<0.001$ and $P=0.002$ respectively).

The subsequent adjuvant treatments were received by the patients with either persistent or recurrent hyperprolactinemia. Nineteen patients who were administered bromocriptine alone achieved normalization of PRL concentrations. Seven patients experienced remission by means of medical plus radiotherapy. Reoperation was required for four patients with continued dopaminergic treatment due to the evidence of tumor regrowth, of whom two had normalization of PRL levels. Four cases with slightly increased PRL concentration without symptoms received no additional therapy, of which one normalized PRL level



Figure 1 Graph showing Kaplan-Meier analysis of time to relapse of hyperprolactinemia in 46 male patients who were in remission after initial surgery. The 5-year recurrence-free survival rate was $77.5 \%(95 \% \mathrm{Cl}, 61.2-87.6 \%)$. 


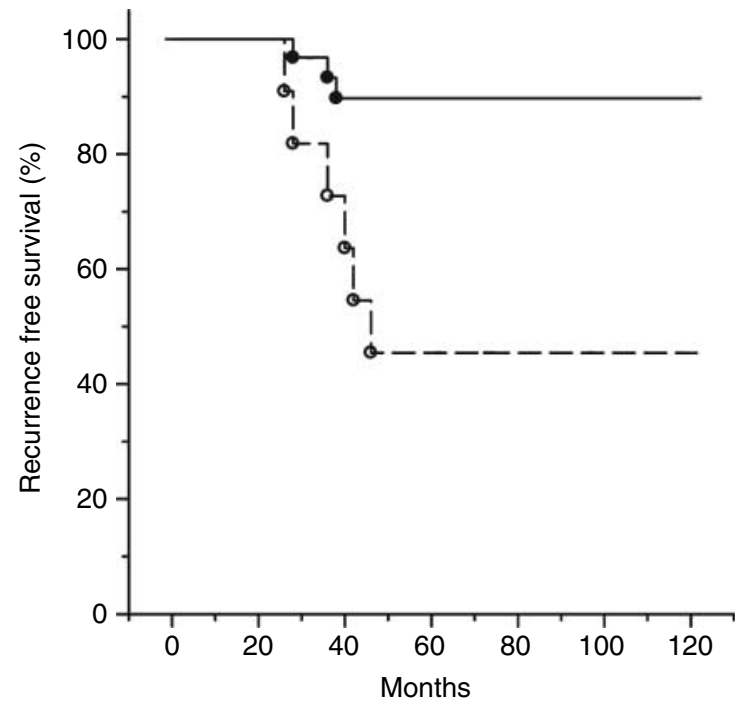

Figure 2 Line graph demonstrating tumor remission according to tumor growth extension in $\mathbf{4 6}$ male patients with a prolactinoma. Significant differences in the 5-year recurrence-free survival rate were found between male intrasellar prolactinomas $(89.7 \%$; $95 \%$ $\mathrm{Cl}, 71.4-96.6 \%$; solid line) and extrasellar prolactinomas (45.5\%; $95 \% \mathrm{Cl}, 16.7-70.7 \%$; dashed line; log-rank test, $P=0.002$ ).

spontaneously 1.5 years after surgery. Despite further treatment with bromocriptine and/or radiotherapy in the remaining patients, PRL levels still remained elevated but the tumor growth was under control. At the last follow-up, the overall remission rate in the absence of DA was $78.8 \%$, and the mean testosterone values were $3.2 \mathrm{ng} / \mathrm{ml}$ but still remained low in 23 patients. One of three patients remained infertile at the end of follow-up.

\section{Discussion}

Primary DA is currently recognized as the 'goldstandard' treatment in most patients with prolactinomas including male prolactinomas (20). Surgery is generally used as a second-line treatment in prolactinomas. Currently, specific guidelines for the treatment of male prolactinomas do not exist $(14,20)$, and the surgical indications are typically made with reference to those for female prolactinomas in most cases $(17,20)$. In our study, the overall initial remission rate $(52.9 \%)$ was in good agreement with previous reports obtained in a mixed cohort of women and men with prolactinomas with remission rate ranging from 53.2 to $64.2 \%$ (16, 17). In contrast to the previous reports including only male prolactinomas, the overall initial remission rate in our study is slightly higher than the previous report (45\%) by Calle-Rodrigue et al. (19), and is higher than the other published data ranging from 25.9 to $38 \%$ $(13,16,22,25)$. The most plausible explanation for the discrepant outcomes might be in part because the subjects included different ratio of micro- versus macroadenomas or had different frequency of cavernous sinus invasion, in part because of the development of technique and equipments. Our results in microprolactinomas are comparable to the two previous reports including only male microprolactinomas (72.7-84.6\%) $(14,15)$, and the remission rates of both microprolactinomas and intrasellar macroadenomas treated with surgery alone are well comparable with those treated with pharmacotherapy alone $(80-83 \%)(26,27)$. The rate of PRL normalization (44.9\%) of male macroprolactinomas, especially extrasellar macroadenomas, was significantly lower than that of the previous findings $(75.6-79 \%)$ treated with DA alone $(26,27)$. However, the remission rate of macroadenomas was higher than the early data from a decade ago ranging from 4.3 to $38 \%(13,25)$. Our results were slightly lower than the previous outcomes of female prolactinomas treated with surgery. The most plausible explanation might be associated with the higher frequency of extrasellar and invasive adenomas in men relative to women (28). Almost all patients in our study exhibited improvement in clinical symptoms, even though patients showed persistent hyperprolactinemia postoperatively.

To our knowledge, no previous study has exploited the multivariate analysis method to identify the independent role of the different variables in surgical outcomes of male prolactinomas. With regard to the difference between gender and surgical outcome, it still remains controversial. Logistic regression analysis by Losa et al. (16) showed that the preoperative PRL level was the only predictive factor of early surgical remission. Kreutzer et al. (17) reported that preoperative PRL level, tumor size, and growth extension were the independent predictors of outcomes. Both groups investigated a mixed cohort of male and female patients but did not demonstrate any effect of gender on surgical outcomes suggestive of the minor influence of sex on surgical results. Recently, Raverot et al. (22) illustrated that male sex was associated with an early negative surgical outcome by univariate analysis, whereas no significance was found by multiple logistic regression analysis. To sum up, male sex does not exert crucial effect on surgical outcomes of prolactinomas. However, male gender was found to be closely associated with recurrence of hyperprolactinemia after DA withdrawal by Colao et al. (5). In the present study, the preoperative PRL level and tumor invasion were found to be associated with early poor surgical outcomes by multivariate analysis, in line with most of the previous literature $(16,17,22)$.

The impact of preoperative DA therapy on surgical outcome is still under debate $(7,29,30)$. Some neurosurgeons have reported that tumors medically treated preoperatively were difficult to resect and less likely to achieve normal prolactin levels owing to increased consistency of the adenoma $(31,32)$. And some have shown no adverse outcome of pre-treatment with these agents (33). However, Fahlbusch (29) and 
Thomson (34) indicated that patients with macro- or microprolactinomas had improved outcomes treated with bromocriptine before surgery. In addition, Fahlbusch et al. (30) observed that after withdrawal of DA about 2-3 months before surgery of microprolactinomas, postoperative PRL results did not worsen. Sughrue et al. (35) demonstrated recently that a greater percentage of the tumor could be resected after DA therapy, and thus, better control of the PRL level would be obtained. In our study, no important influence of preoperative DA administration on surgical outcomes was found. Furthermore, most studies including the present data found that tumor cytoreduction after surgery typically elevates the responsiveness of DA and hence decreases the required dosage, even if surgery is not curative $(36,37)$.

Recurrence is a common issue bothering pituitary surgeons for prolactinomas. The recurrence rates in the previous literature $(19,25)$ varied from 0 to $40 \%$. The difference might be associated with the different standard of hyperprolactinemia recurrence and the different ratio of micro- and macroadenomas. We found that $19.6 \%$ of patients experienced relapse of hyperprolactinemia. Recurrence rate of macroadenomas in the series was lower than the report by Wilson (25). And the recurrence rates of microprolactinomas and intrasellar macroadenomas were considered to be the most favorable ones, whereas that of extrasellar macroadenomas was the worst. With regard to the time of relapse, our data were consistent with prior findings $(16,38)$. Univariate analysis of the time to relapse demonstrated that the postoperative PRL level and growth extension were associated with recurrence, whereas Losa et al. (16) reported in a mixed series that extrasellar extension of the tumor influenced the risk of recurrence without postoperative PRL levels. And Amar et al. (38) demonstrated that a postoperative PRL below $10 \mathrm{ng} / \mathrm{ml}$ predicted remission with $100 \%$ accuracy during the 5-year follow-up.

Subsequent adjuvant treatments were received by most male patients with persistent or recurrent hyperprolactinemia. Of these patients, $60.4 \%$ achieved normalization of PRL concentration, which was slightly lower than the previous report of a mixed series (16). At the latest follow-up, the total remission rate of our series might be superior to that of withdrawal of medication therapy $(5,6)$.

Our paper descriptively exhibits the strengths and weaknesses of surgical treatment of male prolactinomas at a specialized center. Transsphenoidal surgery could provide selected patients with immediate normalization of PRL levels, without the need for long-term medication administration. Strict selection of male patients with microadenomas and intrasellar macroadenomas with low preoperative PRL levels is of uttermost importance to obtain high likelihood of short- and long-term remission, as suggested in previous studies $(16,17,24)$. It is equally important to have surgeons possessing broad experience and skilled techniques to perform these procedures. Under the circumstances, excellent surgical results with little morbidity and a low recurrence rate could be achieved by transsphenoidal microsurgery for male micro- and intrasellar macroprolactinomas. As for male extrasellar macroprolactinomas, surgery followed by adjuvant therapy when necessary is required. Consequently, transsphenoidal surgery is a viable treatment alternative for male prolactinomas. However, further studies with more patients and longer follow-up are required to confirm the present results.

\section{Declaration of interest}

The authors declare that there is no conflict of interest that could be perceived as prejudicing the impartiality of the research reported.

\section{Funding}

This work was supported by the Natural Science Foundation of Shandong Province (grant numbers Y2008C64 and Y2006C75) and the Shandong Provincial Outstanding Research Award Fund for Young Scientists (grant number 2007BS03050).

\section{Acknowledgements}

The authors thank Prof. Guangwei Wei (Shandong University School of Medicine, Jinan, People's Republic of China) for help with the English revision.

\section{References}

1 Colao A. The prolactinoma. Best Practice and Research. Clinical Endocrinology and Metabolism 200923 575-596. (doi:10.1016/j. beem.2009.05.003)

2 Klibanski A. Clinical practice. Prolactinomas. New England Journal of Medicine 2010362 1219-1226. (doi:10.1056/NEJM cp0912025)

3 Ciccarelli A, Daly AF \& Beckers A. The epidemiology of prolactinomas. Pituitary 20058 3-6. (doi:10.1007/s11102005-5079-0)

4 Nishioka H, Haraoka J \& Akada K. Growth potential of prolactinomas in men: is it really different from women? Surgical Neurology $2003 \quad 59$ 386-390. (doi:10.1016/S0090-3019 (03)00012-0)

5 Colao A, Di Sarno A, Guerra E, Pivonello R, Cappabianca P, Caranci F, Elefante A, Cavallo LM, Briganti F, Cirillo S \& Lombardi G. Predictors of remission of hyperprolactinaemia after long-term withdrawal of cabergoline therapy. Clinical Endocrinology 200767 426-433. (doi:10.1111/j.1365-2265. 2007.02905.x)

6 Dekkers OM, Lagro J, Burman P, Jorgensen JO, Romijn JA \& Pereira AM. Recurrence of hyperprolactinemia after withdrawal of dopamine agonists: systematic review and meta-analysis. Journal of Clinical Endocrinology and Metabolism 201095 43-51. (doi:10.1210/jc.2009-1238)

7 Schlechte JA. Long-term management of prolactinomas. Journal of Clinical Endocrinology and Metabolism 200792 2861-2865. (doi:10.1210/jc.2007-0836)

8 Colao A, Di Sarno A, Pivonello R, Di Somma C \& Lombardi G. Dopamine receptor agonists for treating prolactinomas. Expert Opinion on Investigational Drugs 200211 787-800. (doi:10.1517/ 13543784.11.6.787) 
9 Chanson P, Borson-Chazot F, Chabre O \& Estour B. Drug treatment of hyperprolactinemia. Annales d'Endocrinologie $2007 \mathbf{6 8}$ 113-117. (doi:10.1016/j.ando.2007.03.003)

10 Delgrange E, Trouillas J, Maiter D, Donckier J \& Tourniaire J. Sexrelated difference in the growth of prolactinomas: a clinical and proliferation marker study. Journal of Clinical Endocrinology and Metabolism 199782 2102-2107. (doi:10.1210/jc.82.7.2102)

11 Verhelst J, Abs R, Maiter D, van den Bruel A, Vandeweghe M, Velkeniers B, Mockel J, Lamberigts G, Petrossians P, Coremans P, Mahler C, Stevenaert A, Verlooy J, Raftopoulos C \& Beckers A. Cabergoline in the treatment of hyperprolactinemia: a study in 455 patients. Journal of Clinical Endocrinology and Metabolism 1999 84 2518-2522. (doi:10.1210/jc.84.7.2518)

12 Olafsdottir A \& Schlechte J. Management of resistant prolactinomas. Nature Clinical Practice. Endocrinology and Metabolism 20062 552-561. (doi:10.1038/ncpendmet0290)

13 Berezin M, Shimon I \& Hadani M. Prolactinoma in 53 men: clinical characteristics and modes of treatment (male prolactinoma). Journal of Endocrinological Investigation 199518 436-441.

14 Wolfsberger S, Czech T, Vierhapper H, Benavente R \& Knosp E. Microprolactinomas in males treated by transsphenoidal surgery. Acta Neurochirurgica 2003145 935-940. (doi:10.1007/s00701003-0134-y)

15 Gimenez-Roqueplo AP, Dupuy M, Delalande O, Visot A, Jedynak CP, Peillon F \& Derome PJ. Prolactin microadenoma in men. Study of 14 cases. Annales de Médecine Interne 1992143 94-97.

16 Losa M, Mortini P, Barzaghi R, Gioia L \& Giovanelli M. Surgical treatment of prolactin-secreting pituitary adenomas: early results and long-term outcome. Journal of Clinical Endocrinology and Metabolism 200287 3180-3186. (doi:10.1210/jc.87.7.3180)

17 Kreutzer J, Buslei R, Wallaschofski H, Hofmann B, Nimsky C, Fahlbusch R \& Buchfelder M. Operative treatment of prolactinomas: indications and results in a current consecutive series of 212 patients. European Journal of Endocrinology 2008158 11-18. (doi:10.1530/EJE-07-0248)

18 Nomikos P, Buchfelder M \& Fahlbusch R. Current management of prolactinomas. Journal of Neuro-Oncology $2001 \mathbf{5 4} 139-150$. (doi:10.1023/A:1012905415868)

19 Calle-Rodrigue RD, Giannini C, Scheithauer BW, Lloyd RV, Wollan PC, Kovacs KT, Stefaneanu L, Ebright AB, Abboud CF \& Davis DH. Prolactinomas in male and female patients: a comparative clinicopathologic study. Mayo Clinic Proceedings 199873 1046-1052. (doi:10.4065/73.11.1046)

20 Casanueva FF, Molitch ME, Schlechte JA, Abs R, Bonert V, Bronstein MD, Brue T, Cappabianca P, Colao A, Fahlbusch R, Fideleff H, Hadani M, Kelly P, Kleinberg D, Laws E, Marek J, Scanlon M, Sobrinho LG, Wass JA \& Giustina A. Guidelines of the Pituitary Society for the diagnosis and management of prolactinomas. Clinical Endocrinology 200665 265-273. (doi:10.1111/ j.1365-2265.2006.02562.x)

21 de Paiva Neto MA, Vandergrift A, Fatemi N, Gorgulho AA, Desalles AA, Cohan P, Wang C, Swerdloff R \& Kelly DF. Endonasal transsphenoidal surgery and multimodality treatment for giant pituitary adenomas. Clinical Endocrinology 201072 512-519. (doi:10.1111/j.1365-2265.2009.03665.x)

22 Raverot G, Wierinckx A, Dantony E, Auger C, Chapas G, Villeneuve L, Brue T, Figarella-Branger D, Roy P, Jouanneau E, Jan M, Lachuer J \& Trouillas J. Prognostic factors in prolactin pituitary tumors: clinical, histological, and molecular data from a series of 94 patients with a long postoperative follow-up. Journal of Clinical Endocrinology and Metabolism $2010 \quad 95$ 1708-1716. (doi:10.1210/jc.2009-1191)

23 Shou XF, Li SQ, Wang YF, Zhao Y, Jia PF \& Zhou LF. Treatment of pituitary adenomas with a transsphenoidal approach. Neurosurgery 200556 249-256. (doi:10.1227/01.NEU.000014 7976.06937.1D)
24 Tyrrell JB, Lamborn KR, Hannegan LT, Applebury CB \& Wilson CB. Transsphenoidal microsurgical therapy of prolactinomas: initial outcomes and long-term results. Neurosurgery 1999 44 254-261. (doi:10.1097/00006123-199902000-00006)

25 Molitch ME, Thorner MO \& Wilson C. Management of prolactinomas. Journal of Clinical Endocrinology and Metabolism 199782 996-1000. (doi:10.1210/jc.82.4.996)

26 Colao A, Vitale G, Cappabianca P, Briganti F, Ciccarelli A, De Rosa M, Zarrilli S \& Lombardi G. Outcome of cabergoline treatment in men with prolactinoma: effects of a 24-month treatment on prolactin levels, tumor mass, recovery of pituitary function, and semen analysis. Journal of Clinical Endocrinology and Metabolism 200489 1704-1711. (doi:10.1210/jc.2003-030979)

27 Pinzone JJ, Katznelson L, Danila DC, Pauler DK, Miller CS \& Klibanski A. Primary medical therapy of micro- and macroprolactinomas in men. Journal of Clinical Endocrinology and Metabolism 2000 85 3053-3057. (doi:10.1210/jc.85.9.3053)

28 Delgrange E, Daems T, Verhelst J, Abs R \& Maiter D. Characterization of resistance to the prolactin-lowering effects of cabergoline in macroprolactinomas: a study in 122 patients. European Journal of Endocrinology 2009160 747-752. (doi:10.1530/EJE09-0012)

29 Fahlbusch R, Buchfelder M \& Schrell U. Short-term preoperative treatment of macroprolactinomas by dopamine agonists. Journal of Neurosurgery 198767 807-815. (doi:10.3171/jns.1987.67.6. 0807)

30 Fahlbusch R, Buchfelder M, Rjosk HK \& von Werder K. Influence of preoperative bromocriptine therapy on success of surgery for microprolactinoma. Lancet 19842 520. (doi:10.1016/S01406736(84)92596-0)

31 Landolt AM \& Osterwalder V. Perivascular fibrosis in prolactinomas: is it increased by bromocriptine? Journal of Clinical Endocrinology and Metabolism 198458 1179-1183. (doi:10. 1210/jcem-58-6-1179)

32 Bevan JS, Adams CB, Burke CW, Morton KE, Molyneux AJ, Moore RA \& Esiri MM. Factors in the outcome of transsphenoidal surgery for prolactinoma and non-functioning pituitary tumour, including pre-operative bromocriptine therapy. Clinical Endocrinology 198726 541-556. (doi:10.1111/j.1365-2265. 1987.tb00809.x)

33 Giovanelli M, Losa M, Mortini P, Acerno S \& Giugni E. Surgical results in microadenomas. Acta Neurochirurgica. Supplement 1996 65 11-12.

34 Thomson JA, Davies DL, McLaren EH \& Teasdale GM. Ten year follow up of microprolactinoma treated by transsphenoidal surgery. BMJ 1994309 1409-1410.

35 Sughrue ME, Chang EF, Tyrell JB, Kunwar S, Wilson CB \& Blevins LS Jr. Pre-operative dopamine agonist therapy improves post-operative tumor control following prolactinoma resection. Pituitary 200912 158-164. (doi:10.1007/s11102-008-0135-1)

36 Liu J \& Couldwell W. Contemporary management of prolactinomas. Neurosurgical Focus 200416 1-11. (doi:10.3171/foc.2004. 16.4.3)

37 Ozgen T, Oruckaptan HH, Ozcan OE \& Acikgoz B. Prolactin secreting pituitary adenomas: analysis of 429 surgically treated patients, effect of adjuvant treatment modalities and review of the literature. Acta Neurochirurgica $1999 \quad \mathbf{1 4 1} 1287-1294$. (doi:10.1007/s007010050432)

38 Amar AP, Couldwell WT, Chen JCT \& Weiss MH. Predictive value of serum prolactin levels measured immediately after transsphenoidal surgery. Journal of Neurosurgery $2002 \quad 97$ 307-314. (doi:10.3171/jns.2002.97.2.0307)

Received 6 January 2011

Accepted 20 January 2011 